\title{
Menekan Potensi Korosi Base Plate Pondasi Tangki Dengan Metode Drainase Horizontal Geopipe Dibawah Pondasi
}

\author{
Sulardi \\ Prodi Teknik Sipil UniversitasTridharma, Jln.A.W Syahrani. No.7, Balikpapan \\ e-mail: sulardikm61@yahoo.com
}

\begin{abstract}
ABSTRAK
Salah satu permasalahan yang terjadi di kilang adalah terjadinya korosi pada base plate bottom tangki yang berpotensi mengakibatkan pencemaran lingkungan dan potensi kebakaran. Tujuan penelitian ini adalah untuk memberikan gambaran pencegahan korosi base plate pondasi tangki minyak dengan metode drainase bawah pondasi. Laporan penelitian ini adalah success story metode perbaikan pondasi dan base plate pondasi tangki crude oil di Unit Hydration Plan PT. Pertamina RU V yang dilakukan dengan metode perbaikan dengan memodifikasi sitim drainase bawah pondasi dari kondisi semula menggunakan urugan tanah berpasir yang dimodofikasi dengan memasang lapisan kedap air (HDPE Sheet) dan horizontal geopipe dibawah pondasi. Hasil penelitian menunjukkan setelah tangki yang digunakan selama enam bulan dengan kondisi terekspos bebas dan dilakukan pemeriksaan terhadap sisi bawah bottom base plate tidak terindikasi korosi dan dengan kondisi coating tetap dalam keadaan baik. Hasil penelitian ini menunjukan bahwa metode drainase bawah pondasi terbukti dapat menekan potensi korosi dan dapat meningkatkan umur pakai base plate tangki. Hasil penelitian ini juga merekomendasikan agar metode drainase bawah pondasi dengan horizontal geopipe digunakan pada program perbaikan base plate pondasi dan pondasi tangki yang mengalami penurunan, terutama pada tangki eksisting yang jenis pondasinya masih menggunakan tanah dasar berpasir yang ditinggikan dan dipadatkan.
\end{abstract}

Kata Kunci

Korosibase plate, lapisan kedap air, horizontal geopipe.

\section{PENDAHULUAN}

\subsection{Latar Belakang Masalah}

Kawasan kilang PT. Pertamina RU V Balikpapan terdiri dari dua kawan utama yaitu kilang utara yang merupakan kawasan instalasi dan peralatan kilang, tangki dan kawasan uitilities. Sedangkan kawasan kilang selatan adalah kawasan instalasi tangki dan perkapalan hasil produksi maupun bahan baku crude oil. Kawasan kilang berada dikawasan pantai Teluk Balikpapan dengan elevasi dasar tanah adalah 1,5 - 3.5 meter diatas permukaan air laut [1,2]. Diperkirakan kawasan kilang pada awalnya adalah kawasan rawa-rawa, kawasan kawasan dataran rendah dan kawasan tergenang air yang pada saat pelaksanaan pembangunan kilang dilakukan pengurugan untuk memperoleh elevasi permukaan tanah kawasan kilang memiliki ketinggian (elevasi) permukaan tanah yang cukup aman terhadap limpasan banjir permukaan, limpasan air hujan dan genangan akibat pasang tinggi air laut. Elevasi permukaan tanah tanah dasar ini masih dipertahankan hingga saat ini.

\subsection{Permasalahan Penelitian}

Permasalahan yang dihadapi adalah terjadinya kebocoran bottom plate tangki (sub standard condition) yang mengakibatkan terbuangnya minyak, terpaparnya lingkungan disekitarnya dengan bocoran minyak dan adanya potensi kebakaran (unsafe condition). Tindakan preventif yang dilakukan pada kesempatan pertama adalah dengan menghentikan operasi tangki, memindahkan isi minyak didalam tangki yang bocor ke yang tangki lain dan menutup jalan akses ke tangki agar tidak membahayakan. Namun hal ini belum menyelesaikan permasalahan karena sumber kebocoran tangki belum ditemukan dan belum dilakukan perbaikan.

Diprediksi faktor penyebab kebocoran adalah material base plate pondasi tangki terkorosi. Sedangkan penyebab permasalahan kebocoran base plate pondasi tangki diperkirakan karena material pelindung base plate tangki rusak, base plate kontak langsung dengan tanah dasar yang lembab dan basah karena elevasi base palte pondasi yang rendah [3], lingkungan tanah dasar dibawah pondasi yang bersifat korosifdengan kecenderungan sering terendam air dan kondisinya basah.

Untuk itu penelitian ini dirasa sangat penting dilakukan dalam rangka menemukan jawaban atas pertanyaan penelitian yakni faktor, penyebab dan lokasi kebocoran base plate pondasi tangki serta metode perbaikannya sehingga tangki dapat difungsikan kembali sebagaimana sediakala 
dengan baik dan aman. Jika permasalahan ini tidak segera diselesaikan dikawatirkan akan mengakibatkan tercemarnya lingkungan tanah disekitar pondasi, tercemarnya lingkungan perairan dan ada potensi permasalahan sewaktu-waktu paparan uapminyak (vapour) dapat mengalami flash dan terbakar.

\subsection{Rumusan dan Asumsi Masalah}

\subsubsection{Penelitian}

Korosi base plate pondasi tangki identik dengan degradasi material pelat baja pondasi tangki akibat kondisi tanah yang lembab dan basaah (soil corrosion) $[2,3,6]$, kondisi tanah dasar yang asam dan aktivitas mikrobiologi alami tanah. Untuk itu fokus penelitian adalah mencegah agar tanah dasar tidak basah/ lembab dan mencegah kelembaban kontak dengan sisi bawah base plate pondasi tangki. Metode yang direncanakan untuk mengatasi permasalahan tersebut adalah dengan meninggikan posisi pondasi tangki sampai dengan batas aman sesuai standard [4], memasang lapisan pelindung kedap air dan memasang pipa drainase bawah tanah (geopipe) agar kondisi tanah dasar dibawah pondasi base plate tangki selalu kering dan aman terhadap genangan air. Dengan metode perbaikan ini diasumsikan, jika kondisi tanah dasar dibawah pondasi tangki selalu dapat dijaga dalam kondisi kering (drained) maka potensi korosi base plate pondasi tangki dapat dicegah.

\subsection{Pertanyaan Penelitian}

Pertanyaan yang dikembangkan dan diharapkan akan ditemukan jawabannya melalui penelitian ini dalam rangka menjawab faktor dan penyebab permasalahan adalah :

1. Bagaimana gambaran terjadinya korosi pada base plate tangki?

2. Bagaimana gambaran metode drainase horizontal menggunakan geopipe dibawah pondasi tangki ?

3. Bagaimana gambaran metode perbaikan pondasi tangki yang dilakukan dengan cara memasang modifikasi horizontal geopipe dibawah pondasi dan bagaimana hasil perbaikannya?

\subsection{Tujuan Penelitian}

Tujuan yang hendak dicapai melalui penelitian ini adalah :

1. Memberikan gambaran faktor dan penyebab korosi base plate tangki

2. Memberikan gambaran metode drainase horizontal geopipe dibawah pondasi

3. Memberikan gambaran metode perbaikan pondasi tangki dengan modifikasi horizontal geopipe dibawah pondasi dan hasil perbaikanya.

\section{TINJAUAN PUSTAKA}

\subsection{Korosi Tanah}

Korosi adalah kerusakan atau degradasi material logam akibat reaksi redoks antara logam dengan berbagai macam zat di lingkungan sekitarnya yang menghasilkan senyawa-senyawa yang tidak dikehendaki [5]. Dalam bahasa sehari-hari, korosi disebut perkaratan (perkaratan besi). Korosi banyak jenisnya dan tergantung dengan lingkungannya, diantaranya adalah korosi tanah (soil corrosion). Korosi tanah adalah korosi logam yang terjadi akibat material logam berinteraksi dengan material tanah [6].

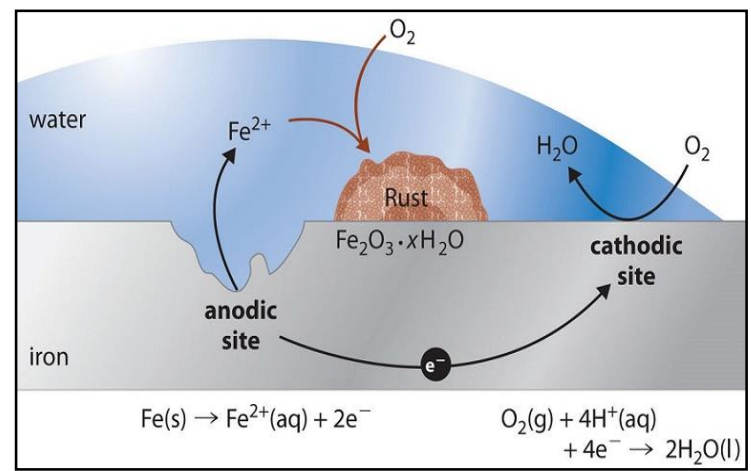

Gambar 1. Proses korosi (W.H Allor, 1981)

Faktor-faktor yang berpengaruh terhadap soil Corrosion adalah karakteristik aerasi dan permeabilitas tanah, kandungan garam-garam dalam tanah, tingkat keasaman tanah dan adanya species ionic pada tanah seperti chloride atau aktivitas mikrobiologi seperti bakteri [2,5,6]. Karakterstik physical tanah yang kasar memiliki sifat drainase yang baik sehingga baja yang terkorosi pada lingkungan ini laju korosi hampir sama dengan laju korosi baja yang terekspos dengan lingkungan atmosfer. Bagian bajayang terkena oksigen dengan kosentrasi rendah akan menjadi anodik dibanding dengan bagian baja yang terkena kadar oksigen tinggi. Tanah yang paling korosif adalah tanah dengan kosentrasi garam tinggi karena garam menjadikan tanah akan lebih konduktif dalam mengalirkan elektron atau dengan kata lain tingkat tahanan (resistivity) tanah rendah. Tingkat keasamaan tanah dari pH. 3,5 bersifat asam dan korosif kuat sampai pH.9,5 yang bersifat alkaline kuat cenderung kurang korosif. Parameter tanah yang mempengaruhi tingkat korosifitas adalah kandungan air, derajat aerasi, tingkat keasaman $(\mathrm{pH})$, soil resisvity, redox potential, kandungan sulfates, dan kandungan chlorides dalam tanah [5]. 


\subsection{Pondasi Tangki}

Pondasi tangki adalah bagian dari bangunan konstruksi tangki yang berfungsi sebagai penahan beban bangunan tangki untuk diteruskan ke lapisan tanah dasar dibawahnya tanpa terjadi keruntuhan $[3,7]$.Untuk itu struktur pondasi dituntut memiliki daya yang besar dan stabilitas yang kokoh agar dapat mendukung operasional tangki dengan baik dan aman. Sesuai spesifikasi standard API 650 [4], jenis-jenis pondasi yang digunakan adalah pondasi tanah tanpa cincin dinding,pondasi tanah dengan cincin beton, pondasi tanah dengan ringwall daripecahan batu dan kerikil, dan pondasi tatakan beton.

Faktor-faktor penentu didalam desain pondasi tangki meliputi faktor keselamatan dengan faktor keselamatan 1.5-3.5, ketersediaan lokasi lahan, metode peningkatan daya dukung dan stabilitas tanah, dan tinggi permukaan dasar tanki sebesar minimum satu feet $(30,5 \mathrm{Cm})$, untuk memberikan drainage dan menjaga agar dasar tanki tetap kering dan kompensasi penurunan (settlement) dengan menambahkan tinggi pondasi setinggi enam inch (15 $\mathrm{Cm})$.

\subsection{Geopipe}

Geopipe adalah Pipa HDPE corrugated berlubang dan digunakan sebagai material drainase (subsoil drainage) [2]. Geopipe ini bisa mencegah terjadinya genangan air dibawah tanah dan pada umumnya digunakan untuk sistem drainase bawah lapangan bola, golf, agriculture, retaining wall, switch yard dan sejenisnya. Geopipe adalah bentuk geosynthetic dalam bentuk gulungan (coil) dengan ukuran panjang per coil 30-50 m [2]. Geopipe bersifat fleksibel, elastis, tahan terhadap korosif, chemical dan sangat kuat terhadap beban berat. Geopipe digunakan dengan dipendam dibawah pondasi, dibawah tanah, dibawah bebatuan dan material pondasi lainnya di bawah permukaan sebagai bagian integral konstruksi disite.

Geopipe adalah berbahan dasar pipa plastik HDPE yang dipakai untuk sistim drainase bawah pondasi dan bawah bangunan, berfungsi meresapkan, menampung dan mengalirkannya ke saluran air yang posisinya lebih rendah. Terdapat dua jenis geopipe yakni, single wall (light duty) dan doble wall (heavy duty) yang masing-masing jenis tersebut terdapat terdapat dalam dua jenis pula yaitu jenis perforated (berlubang dan berpori) dan jenis non perforated (tak berlubang dan tidak berpori). Kelebihan geopipe adalah berrsifat flexible, penginstalan lebih cepat, penanganan mudah, tahan terhadap korosi, kapasitas pengaliran yang besar, dan mempunyai kuat tekan yang baik.

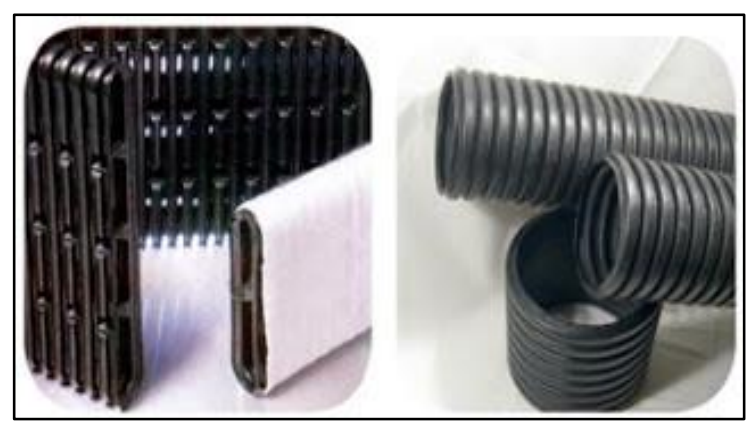

Gambar 2. Geopipe HDPE perforated corugated pipe

Geopipe dapat digunakan pada drainase konstruksi komersial dan perumahan, drainase bawah permukaan pada konstruksi jalan, drainase untuk tambang, lahan konstruksi, lahan agrikultur, pondasi bangunan, lapangan olahraga dan tempat rekreasi, untuk dinding penahan tanah dan pada penelitian ini digunakan sebagai drainase pengendali korosi base plate tangki.

\section{METODE PENELITIAN}

\subsection{LokasiPenelitian}

Penelitianini dilakukandi kilang PT. Pertamina RU $\mathrm{V}$ Balikpapan tepatnya dikawasan instalasi tangki dan dilakukan pada saat pelaksanaan pekerjaan overhaul tangki Long Residu (tangki No. O3) dikawasan kilang utara [3]. Pekerjaan overhaul tangki meliputi pekerjaan mekanikal tangki, perbaikan peralatan rotating berupa mesin-mesin penunjang operasi tangki, perbaikan peralatan instrumentasi dan kelistrikan tangki, perbaikan sistim utilitas tangki dan perbaikan sistim fire system tangki. Namun pada penelitian ini membatasi diri pada perbaikan konstruksi pondasi tangki dengan tetap mengacu kepada spesifikasi typical section through tank foundations dan details of standard foundation.

\subsection{Metode Penelitian}

Penelitianini menggunakan metode penelitian aplikasi yakni aplikasi proteksi korosi base plate pondasi tangki dengan modifikasi pemasangan lapisan kedap air HDPE Sheet dan modifikasi pemasangan alat pengeringan air tanah dengan geopipe. Penelitian ini sekaligus adalah catatan success story aplikasi metode horizontal geopipe dibawah pondasi untuk mencegah korosi base plate pondasi tangki.Permasalahan pondasi tangki adalah salah satu problem geoteknik yang terjadi di kilang (refinery) yang memerlukan solusi yang tepat untuk mencegah kejadian sejenis terjadi kembali.Pada penelitian ini peneliti bertugas sebagai construction inspection engineer dengan fokus tugas pada quality controll (QC), quality acceptance(QA) dan inspection test plant (ITP). 


\subsection{Metode Pendekatan}

Penelitianini menggunakan metode pendekatan studi kasus penanganan masalah korosi pada base plate pondasi tangki Long Residu (O3) di kawasan kilang utara PT. Pertamina RU V dengan aplikasi metode horizontal geopipe. Gambaran struktur pondasi tangki terpasang disite sebagaimana tersaji pada gambar. 2.

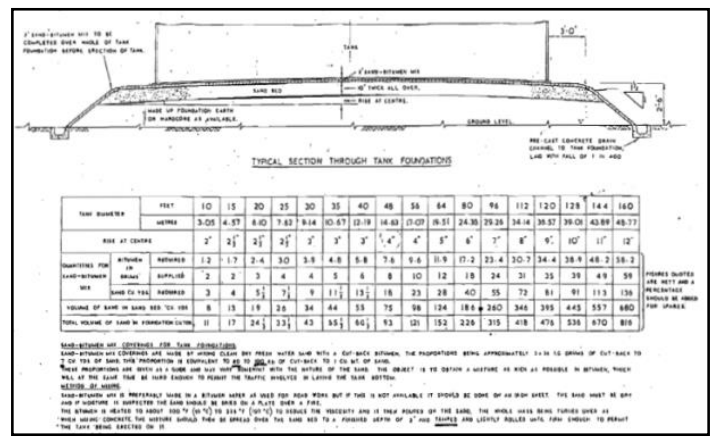

Gambar 3. Drawing design pondasi tangki Long Residu (O3)

Pondasi tangki yang digunakan adalah jenis pondasi dengan typical section through tank foundations berupa peninggian tanah dasar hingga ketinggian 2 feet dan 6 inch $(75 \mathrm{Cm})$, terdiri dari $50 \mathrm{Cm}$ tanah urug yang didatkan, $20 \mathrm{Cm}$ tanah berpasir dan lapis kedap air sandsheet asphalt dengan tebal padat 5 $\mathrm{Cm}$. Konfigurasi pondasi tangki terdiri dari pondasi tangki, bahu tangki selebar 3 feet $(91.5 \mathrm{Cm})$, talud berm dengan kemiringan 60 derajat dan kaki berm terinterkoneksi dengan saluran drainase keliling berm tangki.

\subsection{MetodePerbaikan Pondasi}

\subsubsection{Bahan}

Bahan-bahan yang diperlukan pada pelaksanaan pekerjaan perbaikan pondasi tangki meliputi :

a. Geopipe type HDPE Perforated Corrugated Pipe, diameter 2 Inch

b. Geomembran type HDPE Sheet, tebal. $1.25 \mathrm{~mm}$

c. Pipa oil leak controll, dia. $1 \mathrm{Cm}$

d. Tanah urug jenis lempung kepasiran

e. Semen type 1

f. Hotmox Asphalt

g. Mortar beton, kriteria beton fc-25 Mpa/ Mutu beton K-300

h. Ijuk, sesuai kebutuhan

i. Bahan bekisting dan shoring

j. Bahan-bahan lain sesuai kebutuhan disite.

\subsubsection{Peralatan}

Peralatan kerja digunakan terdiri dari :

a. Alat pengaduk tanah

b. Alat pembentuk dan pemadat tanah

c. Alat kerja pembetonan

d. Alat Jidar ukur

e. Alat Theodolite dan Waterpass

f. Alat kerja bantu lainnya

g. Alat-alat keselamatan kerja dan Alat pelindung diri (APD).

\subsubsection{Metode Kerja}

a. Lakukan site preparation dengan menghilangkan pepohonan, tanaman dan semak belukar

b. Lakukan grubbing dengan pembersihan terhadap rerumput, kerikil, kerakal dan sejenisnya dipermukaan tanah

c. Eksavasi dengan penggalian dan penimbunan kembali tanah, pasir dan bahan-bahan perbaikan tanah lainnya

d. Pasang stake out pondasi tangki, tentukan batasbatas bangun, tentukan elevasi dasar dan pasang patok-patok bantu posisi elevasi

e. Pasang keliling kaki bahu tangki (foot ring berm) pada jarak $115 \mathrm{Cm}$ diluar dinding tangki dengan spesifikasi material beton betulang dengan tinggi $60 \mathrm{Cm}$, tebal $15 \mathrm{Cm}$, dibenamkan kedalam tanah sedalam $30 \mathrm{Cm}$

f. Siapkan campuran soil cement dengan cara menggali tanah pondasi, mencampur dengan semen dengan campuran 1:6, hamparkan dan padatkan sampai elevasi $30 \mathrm{Cm}$ diatas permukaan tanah dasar. Sebelum soil cement dihampat terlebih dahulu dipasang plastic sheet diatas permukaan tanah

g. Pasang tanah urug, hamparkan, ratakan dan padatkan sampai dengan ketinggian total $45 \mathrm{Cm}$ diatas permukaan tanah dasar dan bentuklah permukaan tanah miring 5\% kearah saluran drainase

h. Diatas tanah urug yang telah dipadatkan tersebut (item g) tempatkan geopipe pada delapan arah mata angin dan pasanglah geopipe yang telah dibungkus dengan ijuk setebal $5 \mathrm{Cm}$

i. Urug dengan tanah, hamparkan, ratakan dan padatkan hingga elevasi pondasi tanah urug mencapai $60 \mathrm{Cm}$ dan dengan memastikan posisi geopipe berada diatas saluran drainase

j. Pasang HDPE Sheet menutup seluruh permukaan tanah dasar, jika ada sambungan pastikan lebar sambungan $>20 \mathrm{Cm}$

k. Siapkan campuran soil cement, hamparkan, ratakan dan padatkan sampai dengan elevasi total $67 \mathrm{Cm}$, pasang pipa-pipa kontrol bocoran minyak (oil leak) dengan bahan dasar pipa HDPE dia. $1 \mathrm{Cm}$ dan sisi atas dan sampingnya telah dilubangi dan dibungkus dengan ijuk setebal $3 \mathrm{Cm}$, pastikan pipa miring $5 \%$ kearah bak kontrol

1. Pasang tanah urug berbahan dasar lempung kepasiran (sandy clayed), hamparkan, ratakan dan padatkan sampai elevasi total $75 \mathrm{Cm}$ diatas permukaan tanah dasar

m. Selama masa pemasangan pondasi tanah ini agar dijaga jangan terbasahkan oleh air hujan dengan cara ditutup dengan terpal

n. Pasang lapis flexible pavement berbahan dasar hotmix, ratakan dan padatkandengan tebal padat min. 5.0 $\mathrm{Cm}$ dan pada sisi angular plate tebal padathotmix adalah $10 \mathrm{Cm}$

p. Pasang berm dan talud berm, pastikan ujung luar geopipe tepat diatas saluran drainase, tubuh 
bermdan talud seluruhnya telah tertutup dengan lapis hotmix dengan tebal padat $5 \mathrm{Cm}$

q. Pasang saluran drainase keliling kaki berm dan terinterkoneksi dengan foot ring berm dengan ukuran 30 x $40 \mathrm{Cm}$,tebal $15 \mathrm{Cm}$ danpastikan kemiringannya cukup sehingga dapat mengalirkan air dengan mudah

r. Pasang bak kontrol bocoran minyak dan bak kontrol saluran drainase dengan bahan beton

s. Pekerjaan pondasi tangki dengan modifikasi horizontal geopipe selesai, lakukan joint inspection, siapkan berita acara serah terima hasil pekerjaan dan dilanjutkan dengan pemasangan base plate tangki.

\subsubsection{Indikator Keberhasilan}

a. Pekerjaan persiapan material, peralatan, tenaga kerja dan metodekerja selesai dengan baik dan aman

b. Horizontal geopipe, lapisan kedap air HDPE Sheet dan oil leak controll terpasang dengan baik, telah diuji fungsi dan dapat berfungsi dengan baik dan aman

c. Spesifikasi, bentuk, dimensi dan konfigurasi pondasi tangki sesuai typical section through tank foundations

d. Mematuhi prosedur keselamatan kerja dan tidak terjadi kecelakaan kerja (zero incident).

\section{HASIL DAN PEMBAHASAN}

\subsection{Hasil Penelitian}

Hasil inspeksi teknik setelah base plate pondasi tangki diangkat dengan ketinggian $90 \mathrm{Cm}$ dan dipasang support pengganjal, ditemukan beberapa kondisi sub standard dan unsafe condition berupa sisi luar base plate tangki basah, coating pelindung sisi luar base rusak, korosi lokal di tiga lokasi dengan bentuk lekukan sedalam 2,5-4,5 mm dengan kisaran luasan 10x $15 \mathrm{Cm}$,angular plate telah terkikis dengan bentuk alur-alur paritan, lapis bitumen sandsheet telah rusak hancur dan basah, elevasi pondasi tangki berada pada elevasi $3-5 \mathrm{Cm}$ dibawah tanah dasar disekitarnya dengan kondisi basah. Temuan kerusakan tersebut selanjutnya ditandai dengan kapur inspection (board marker) untuk mempermudah akses pemeriksaan, penelurusan evidence lanjut dan diagnosa faktor penyebab kerusakan lebih lanjut.

Hasil inspeksi teknik setelah pelaksanaan perbaikan adalah pondasi base plate tangki telah ditinggikan sampai dengan elevasi $90 \mathrm{Cm}$ diatas tanah dasar disekliling tangki dengan mengacu kepada elevasi standard benchmarch (BM) PK. 27 dengan lokasi BM di simpang Jalan 104 dan Jalan 107 dan dengan elevasi standard +0.968 . Benchmark PK 27 adalah elevasi standard kilang utara yang juga digunakan sebagai elevasi standard pada pembangunan kilang Balikpapan I, bangunan tangki dan struktur bangunan lain di area kilang utara. Angular plate dan base plate pondasi yang terkorosi, rusak, bergelombang dan bocor telah diganti dengan material pelat baja yang baru dengan spesifikasi material pelat baja sejenis dengan tebal pelat sesuai desain. Sisi bawah base plate telah dipreparasi dengan metode SSPC 10 (blasting) dan dicoating dengan spesifikasi material tolerance dengan tebal coating 300 micron DFT. Lapis kedap air bitumen yang rusak telah diganti dengan spesifikasi material flexible pavement hotmix asphalt dengan tebal padat $5 \mathrm{Cm}$ dan diarea bawah angular plate dengan tebal flexible pavement 7.5 Cm. Pada kaki bahu telah foot ring berm (kaki bahu pondasi tangki) pada jarak 115 $\mathrm{Cm}$ diluar dinding tangki dengan spesifikasi material beton betulang dengan tinggi $60 \mathrm{Cm}$, tebal $15 \mathrm{Cm}$, dibenamkan kedalam tanah sedalam $30 \mathrm{Cm}$.

Tanah dasar dibawah yang terkontaminasi minyak telah dipisahkan dan ganti dengan tanah yang baru, dicampur dengan material semen (soil cement) dengan spesifikasi campuran semen dengan campuran 1:6 (1 sement : 6 tanah), hamparkan dan padatkan sampai elevasi $30 \mathrm{Cm}$ diatas permukaan tanah dasar. Sebelum soil cement dihampat terlebih dahulu dipasang plastic sheet diatas permukaan tanah. Diatas lapis campuran soil cement ini dipasang tanah urug yang dihamparkan, diratakan dan dipadatkan sampai dengan ketinggian total 45 $\mathrm{Cm}$ diatas permukaan tanah dasar sehingga membentuk permukaan tanah miring 5\% kearah saluran drainase. Lapisan tanah urug berikutnya adalah lapis tanah diatas tanah urug yang telah dipadatkan tersebut dan di tempatkan geopipe pada delapan arah mata angin dan pasanglah geopipe yang telah dibungkus dengan ijuk setebal $5 \mathrm{Cm}$.

Diatas lapisan tanah dasar ini adalah urugan tanah yang dihamparkan, diratakan dan dipadatkan sehingga elevasi pondasi tanah urug mencapai 60 $\mathrm{Cm}$ dan telah dipastikan posisi geopipe berada diatas saluran drainase. Diatas lapisan tanah dasar ini telah dipasang HDPE Sheet menutup seluruh permukaan tanah dasar, jika ada sambungan pastikan lebar sambungan > $20 \mathrm{Cm}$ setelah itu diatasnya dihamparkan campuran soil cement, diratakan dan dipadatkan sampai dengan elevasi total $67 \mathrm{Cm}$ dan pasangan pipa-pipa kontrol bocoran minyak (oil leak) dengan bahan dasar pipa HDPE dia. $1 \mathrm{Cm}$ dan sisi atas dan sampingnya telah dilubangi dan telah dibungkus dengan ijuk setebal $3 \mathrm{Cm}$, pasangan pipa-pipa telah dipasang miring $5 \%$ kearah bak kontrol.

Pasangan berm dan talud berm telah sesuai dengan ujung luar geopipe tepat diatas saluran drainase, tubuh berm dan talud seluruhnya telah tertutup dengan lapis hotmix dengan tebal padat $5 \mathrm{Cm}$. Telah dipasang saluran drainase keliling kaki berm dan terinterkoneksi dengan foot ring berm dengan ukuran 30 x $40 \mathrm{Cm}$, tebal $15 \mathrm{Cm}$ dan telah dipastikan kemiringannya dengan mengalirkan air dan terbukti dapat mengalir dengan mudah. Telah dipasang bak kontrol bocoran minyak dan bak 
kontrol saluran drainase dengan bahan beton bertulang. Hasil inspeksi bersama bagian terkait (asset holder, quality control dan teknikal) diketahui hasilnya bahwa pekerjaan persiapan material, peralatan, tenaga kerja dan metodekerja selesai dengan baik dan aman. Horizontal geopipe, lapisan kedap air HDPE Sheet dan oil leak controll terpasang dengan baik, telah diuji fungsi dan dapat berfungsi dengan baik dan aman. Spesifikasi, bentuk, dimensi dan konfigurasi pondasi tangki sesuai typical section through tank foundations. Mematuhi prosedur keselamatan kerja dan tidak terjadi kecelakaan kerja (zero incident).

Hasil pemeriksaan setelah tangki dioperasikan selama enam bulan dan dilakukan pemeriksaan sisi bawah base plate tangki dengan cara membuat lubang uji (sample pit) dan dilakukan pemeriksaan terhadap kondisi sisi bawah base plate pondasi tangki dan diketahui bahwa kondisi base plate pondasi dalam kondisi baik, tidak terindikasi korosi. Lapisan hotmix dalam kondisi baik, tanah lapis pondasi atas tidak ada indikasi terpapar minyak, lapis pondasi bawah (sub grade) dalam kondisi kering dan tidak ada indikasi basah maupun lembab. Setelah pemeriksaan sample pit ditutup kembali dengan campuran soil cement dan diberi tanda dengan board marker. Oleh karena itu diyakini bahwa metode perbaikan yang digunakan memberikan hasil yang baik dan manfaat yang besar dalam pencegahan korosi base plate pondasi tangki.

Hasil perbaikan dari aspek panca mutu (quality, cost, delivery, safety and moral) menunjukan, secara kualitas (quality) metode drainase horizontal dengan geopipe berhasil memperbaiki resistivity tanah dan menurunkan pemicu sifat korosif tanah dasar. Secara cost dapat menekan biaya maintenance akibat kebocoran base plate tangki. Secara delivery telah memiliki metode kerja baru mengatasi masalah kebocoran dan korosi base plate tangki dengan metode drainase horizontal geopipe. Secara safety metode perbaikan dapat meningkat keselamatan tangki terhadap kebocoran dan bahaya kebakaran diarea tangki. Dan secara moral bahwa inovasi yang telah dilakukan dapat meningkatkan konfidensi level pekerja karena dapat mengatasi permasalahan dilingkungan kerjanya dengan baik dan aman.

\subsection{Pembahasan}

Korosi yang terjadi pada sisi bawah base plate pondasi tangki Long Residu (tangki O3) adalah jenis korosi tanah (soil corrosion). Bentuk korosi yang terjadi berupa lekukan-lekukan local corrosion yang terjadi di beberapa lokasi yang mengakibatkan base plate pondasi tangki mengalami penipisan dan bocor. uji keasaman tanah dasar dibawah pondasi tangki menunjukkan, $\mathrm{pH}$ tanah pada kisaran $3.5-$ 5.5 bersifat asam.Korosi base plate pondasi tangki terjadi akibat material base plate kontak langsung dengan tanah dasar yang basah dan lembab.
Dengan sifat tanah dasar pondasi tangki yang porus maka kandungan air tanah dan uap air tanah dengan mudah kontak langsung dengan sisi luar base plate pondasi tangki. Akibat kontak yang terjadi secara berulang dan dalam waktu yang lama maka kandungan garam-garaman, mikroorganisme tanah, resistivity tanah yang rendah dan keasaman tanah yang rendah dengan mudah berinteraksi dengan sisi luar base plate pondasi tangki. Interaksi ini mengakibatkan kerusakan pada coating pelindung base plate pondasi tangki dan terjadilah korosi akibat kondisi tanah.

Kondisi lain yang memicu terjadinya korosi (degradasi material) base plate pondasi tangki adalah akibat turunyan base plate pondasi tangki hingga rata dengan tanah dasar disekitarnya yang memudahkan base plate pondasi tergenang air hujan dan limpasan air permukaan. Hal ini adalah kondisi sub standard, dimana API 650 (App B.41 dan App. B.42) [4] yang mensyaratkan bahwa elevasi base pondasi tangki adalah pada elevasi minimum 1 feet $(30.5 \mathrm{Cm})$ diatas tanah dasar dan tinggi jagaan terhadap kompensasi penurunan 6 Inch dengan tinggi minimum diatas tanah dasar adalah $45.5 \mathrm{Cm}$.

Metode perbaikan dengan modifikasi pondasi tangki menjadi dua layer. Layer pondasi bawah adalah sebagai sub grade zone terdiri dari pasangan foot ring berm, pasangan modifikasi tanah dasar sub grade dengan spesifikasi soil cement, pasangan horizontal drain geopipe danpasangan lapisan kedap air HDPE Sheet. Layer pondasi atas sebagai sub base zone yang terdiri dari pasangantanah urug yang dipadatkan, pasangan leak control pipe dan pasangan lapis hotmix diyakini dapat menekan potensi korosi base plate pondasi tangki.

Foot ring berm berfungsi untuk mencegah pergeseran tanah dasar pondasi kearah samping, soil cement dapat meningkatkan daya dukung dan kekedapan sub grade terhadap pengaruh rembesan air, horizontal drain geopipe dapat menjaga tiris dan keringnya tanah dengan cara mengalirkan jika ada air didalam sub grade, lapis HDPE mencegah rembesan air tanah mencapai lapisan sub base (pondasi atas). Dengan asumsi usia pakai tangki adalah 30 tahun diprediksi pondasi tanah urug hanya akan mengalami penurunan pada kisaran 15-30 Cmsehingga base plate pondasi tangki diperkirakan tetap dalam keadaan safe sesuai usia pakai rencana tersebut.

\section{KESIMPULAN DAN SARAN}

\subsection{Kesimpulan}

1. Jenis korosi adalah korosi tanah (soil corrosion) dengan faktor penyebab faktor lingkungan tanah dan penyebab masalahnya adalah kondisi tanah yang lembab

2. Metode perbaikan dengan memasang drainase horizontal geopipe dibawah pondasi untuk 
menjamin tanah dasar dibawah pondasi selalu kering (drained), memasang lapisan kedap ait HDPE Sheet, memasang layer pondasi atas, memasang pipa kontrol bocoran dan memasang lapis kedap air hotmix

3. Metode modifikasi drainage horizontal geopipe terbukti cocok digunakan danberhasil dengan baik dapat menekan potensi korosi pada base plate pondasi tangki.

\subsection{Saran}

1. Korosi tidak bisa dicegah, yang bisa adalah menghambat korosi dengan cara memasang proteksi agar tidak terjadi korosi

2. Keberhasilan metode perbaikan dengan memasang drainage horizontal geopipe dibawah pondasi yang terbukti cocok digunakan di tangki Long residu (O3) dapat direplikasi untuk mengatasi permasalahan sejenis dilingkungan PT.Pertamina dan unit kerja yang lainnya

3. Agar dilakukan pengecekan terhadap Metode modifikasi drainage horizontal geopipe terbukti cocok digunakan dan berhasil dengan baik menekan potensi korosi pada base plate pondasi tangki.

\section{DAFTAR PUSTAKA}

[1] PT. Pertamina RU V, 2016, Engineering Design Pembangunan Tangki Automotive Diesel Oil, Program ABI Tahun 2016

[2]. Sulardi, 2017, Mencegah Pelunakan Tanah Dasar Dibawah Slab Beton Pelat Lantai Reservoir Dengan Metode Subdrain Geopipe Di RU $V$ Balikpapan, Portal Komet PT. Pertamina Corporate, Jakarta; http://ptmkppwab81.pertamina.com/komet/ searchResult.aspx?ptm;Kodefikasi,No. 171004001.

[3] Sulardi, 2016, Mencegah Settlement Slab Beton Pondasi Peralatan Kilang PT.Pertamina RU V, Portal Komet PT.Pertamina Corporate, Jakarta; http://ptmkppwab81.pertamina.com/komet/ searchResult.aspx?ptm;Kodefikasi,No. 161003018

[4 ] API Standard 650, 2013, Welded Tanks for Oil Storage 11th Edition, API Publishing Services, 1220 L Street, NW, Washington

[5] Sulardi, 2015, Pondasi Tangki dan Peralatan Kilang, Bahan Ajar Bimbingan Teknik, PT. Pertamina RU V Balikpapan

[6] W.H Allor, 1981, Handbook On Corrosion Testing and Evaluation, John Wiley and Son, Inc. New York.
[7] Sulardi, 2016, Mekanika Tanah dan Rekayasa Pondasi, Bahan Ajar Bimbingan Teknik, PT. Pertamina RU V Balikpapan 